\title{
Effects of Synovex One Grass, Revalor-G, or Encore implants on performance of steers grazing for up to 200 days
}

\author{
R. M. Cleale, ${ }^{* 1}$ D. R. Hilbig, ${ }^{*}$ T. H. Short, ${ }^{*}$ S. H. Sweiger,† and T. Gallery† \\ *Zoetis LLC, Parsippany, NJ 07054; and †Gallery Ranch LLC, Dewey, OK 53555
}

\begin{abstract}
Growth rates by cattle $(\mathrm{n}=986)$ grazing for $200 \mathrm{~d}$ and treated with Synovex One Grass (SOG; $150 \mathrm{mg}$ of trenbolone acetate, $21 \mathrm{mg}$ of estradiol benzoate), Revalor-G (REVG; $40 \mathrm{mg}$ of trenbolone acetate, $8 \mathrm{mg}$ of estradiol), or Encore (ENC; $43.9 \mathrm{mg}$ of estradiol) were measured under field use conditions in a randomized complete block design. Blocks were defined by study start dates $(\mathrm{n}=3)$. Crossbred beef cattle, which included steers $(\mathrm{n}=669)$ and bulls castrated upon arrival $(\mathrm{n}=317)$, were stratified by sex and pretreatment BW within start date and assigned to treatments within strata $(\mathrm{n}=328$ to 330 per treatment, initial BW $=191 \pm 2.3 \mathrm{~kg}$ ). Implants were given on d 0 after BW was measured. Blocks were subdivided into pasture management groups with equal numbers from each treatment on each pasture, and animal was the experimental unit. Cattle grazed pastures supplemented with $26 \%$ $\mathrm{CP}$ concentrate and bermudagrass hay during periods of limited forage. Cattle BW were also measured on d 70 and 200; implant status (present or absent) was documented on d 70. Average BW of SOG cattle $(391.2 \mathrm{~kg})$ was greater $(P<0.05)$ on d 200 than REVG $(380.7 \mathrm{~kg})$ or ENC $(381.4$ $\mathrm{kg})$. Between d 0 and 200, ADG by SOG cattle was 1.00 $\mathrm{kg} / \mathrm{d}$, which was greater $(P<0.05)$ than REVG $(0.95$ $\mathrm{kg} / \mathrm{d})$ or ENC $(0.95 \mathrm{~kg} / \mathrm{d})$. Economics were assessed based on cattle purchase and sale prices, implant costs, and morbidity; cattle treated with SOG returned $\$ 24.35$ more than REVG and $\$ 26.77$ more than ENC $(P<0.05)$. Over 200 $\mathrm{d}$, grazing cattle implanted with SOG gained more than REVG or ENC, which increased returns.
\end{abstract}

Key words: cattle, stocker, implant, growth rate, average daily gain

\footnotetext{
The authors declare no conflict of interest.

${ }^{1}$ Corresponding author: ralph.cleale@zoetis.com
}

\section{INTRODUCTION}

Growth-promoting implants are widely considered among the most effective technologies available to beef producers to reduce cost of production because they increase rate of BW gain and improve the efficiency by which dietary nutrients are converted to body mass (Kuhl, 1997; Duckett and Andrae, 2001; Selk et al., 2006). There are many growth-promoting implant products approved for use in cattle, which typically contain at least an estrogenic or androgenic compound, but most contain both. Most implants approved for use in stocker cattle release growth-promoting active ingredients for periods of 80 to $100 \mathrm{~d}$ (Selk et al., 2006). This implies that cattle treated with such products do not benefit from the growthpromoting effects of implants beyond $120 \mathrm{~d}$ unless they are reimplanted (Selk et al., 2006). Revalor-G (REVG; Merck, Madison, NJ) is a combination product approved for use in pastured steers and heifers. The REVG product label does not specify duration of activity but rather indicates that the product contains $8 \mathrm{mg}$ of estradiol and $40 \mathrm{mg}$ of trenbolone acetate in a slow-release delivery system. There are, however, products designed and labeled to deliver anabolic agents for extended durations, thereby reducing labor costs and production losses associated with disruption of cattle performance to gather and reimplant animals in the middle of a grazing season. Estrogen-only products (Ferguson et al., 1988) are available for use in grazing steers, which are effective for $200 \mathrm{~d}$ (Compudose; Elanco, Indianapolis, IN) or 400 d [Encore (ENC); 43.9 mg of estradiol; Elanco]. Recently, Synovex One Grass (SOG; Zoetis, Parsippany, NJ), a combination product containing $21 \mathrm{mg}$ of estradiol benzoate and $150 \mathrm{mg}$ of trenbolone acetate per dose, was shown to be effective for growth promotion in pastured steers and heifers for up to $200 \mathrm{~d}$ (Cleale et al., 2015).

To date, little comparative data have been published that document growth performance of cattle implanted with products commonly administered to pastured cattle. The purpose of this study was to compare growth performance by steers implanted with SOG, REVG, or ENC over a 200-d grazing period. 


\section{MATERIALS AND METHODS}

The study was conducted under the direction of a licensed veterinarian with beef cattle at a commercial stocker enterprise that was operated under routine management practices in accordance with the Animal Welfare Act (7 U.S.C. 54) and FASS (2010).

\section{Animal Acquisition and Processing}

Beef cattle $(\mathrm{n}=1086)$ with British or Continental breeding or both $(\mathrm{BW}=114$ to $250 \mathrm{~kg})$ were acquired in 12 lots between January 5, 2016, and January 28, 2016, and transported less than approximately $235 \mathrm{~km}$ to the study site, located in Copan, Oklahoma. After arrival and until d-0 processing, cattle were maintained in paddocks. At least $14 \mathrm{~d}$ were allowed for cattle to become acclimated to the study facility before treatment administration. Intact bulls $(\mathrm{n}=317)$ were banded at arrival processing, and samples were collected from all cattle to identify those persistently infected with bovine viral diarrhea; bovine viral diarrheapositive animals were excluded from the study. All animals received Dectomax Injection (Zoetis) at a dose based on average purchase BW and were vaccinated with Titanium 5 (Elanco) and Cavalry 9 (Merck). Cattle were identified with duplicate ear tags that did not disclose experimental treatments. As animals were processed, weighed, and given experimental treatments on d 0 , each steer also received Titanium 3 (Elanco), Vision 7 (Merck), and Valbazen $(18 \mathrm{~mL} /$ animal, Zoetis). In addition, as animals were weighed on $\mathrm{d} 70$, they received treatment with LongRange dewormer (5 mL/animal; Merck) and a Tolfenpro Insecticidal ear tag (Bayer, Shawnee Mission, KS).

\section{Study Design and Animal Management}

Animal ( $\mathrm{n}=986$ enrolled) was the experimental unit, and the study used a randomized complete block design. Each block consisted of approximately equal numbers of animals from each treatment that began and ended the study on the same date. The primary blocking criterion was calendar date on d 0 , and animals were enrolled into the study on 3 different calendar dates (Table 1). Enrollment to block 1 on January 25 included 323 steers that averaged $193 \mathrm{~kg}$ ( $\mathrm{n}=110$ to SOG, 108 to REVG, and 105 to ENC). Enrollment to block 2 on February 1 included 327 steers that averaged $191 \mathrm{~kg}(\mathrm{n}=110$ to $\mathrm{SOG}, 110$ to REVG, and 107 to ENC). Finally, enrollment to block 3 on February 8 included 336 steers that averaged $191 \mathrm{~kg}$ (n $=110$ to SOG, 110 to REVG, and 116 to ENC). Steers that completed the study grazed $200 \mathrm{~d}$.

During processing on d 0, animals purchased as bulls that were banded at the time of arrival (at least $14 \mathrm{~d}$ before experimental treatment administration) were examined to confirm testes were not present. Animals within blocks were stratified based on individual d-0 BW and sex at arrival (steers or banded bulls) and then assigned randomly to treatments within strata. Animals within blocks were further subdivided into management cohorts consisting of approximately equal numbers of animals from each of the 3 treatments that remained together throughout the

Table 1. Summary of animal enrollment

\begin{tabular}{lccc} 
& \multicolumn{3}{c}{ Treatment $^{1}$} \\
\cline { 2 - 4 } Item & SOG & REVG & ENC \\
\hline Block 1 & & & \\
No. of cattle enrolled & 110 & 108 & 105 \\
No. of steers, banded bulls & 85,25 & 83,25 & 86,19 \\
Weight d 0, kg & 193.6 & 193.2 & 192.0 \\
Treatment date & Jan. 25, 2016 & Jan. 25, 2016 & Jan. 25, 2016 \\
Completion date & Aug. 12, 2016 & Aug. 12, 2016 & Aug. 12, 2016 \\
Block 2 & & & \\
No. of cattle enrolled & 110 & 110 & 107 \\
No. of steers, banded bulls & 69,41 & 67,43 & 66,41 \\
Weight d 0, kg & 190.9 & 189.9 & 192.1 \\
Treatment date & Feb. 1, 2016 & Feb. 1, 2016 & Feb. 1, 2016 \\
Completion date & Aug. 19,2016 & Aug. 19, 2016 & Aug. 19, 2016 \\
Block 3 & & & \\
No. of cattle enrolled & 110 & 110 & 116 \\
No. of steers, banded bulls & 70,40 & 69,41 & 74,42 \\
Weight d 0, kg & 192.5 & 189.6 & 190.0 \\
Treatment date & Feb. 8, 2016 & Feb. 8, 2016 & Feb. 8, 2016 \\
Completion date & Aug. 26, 2016 & Aug. 26, 2016 & Aug. 26, 2016 \\
\hline
\end{tabular}

${ }^{1} \mathrm{SOG}=$ Synovex One Grass (Zoetis, Parsippany, NJ); REVG = Revalor-G (Merck, Madison, $\mathrm{NJ}) ; \mathrm{ENC}=$ Encore $($ Elanco, Indianapolis, IN). 
study. Two pasture management groups were created from block 1 cattle ( $\mathrm{n}=163$ for group $1 ; \mathrm{n}=160$ for group 2 ), 2 pasture management groups from block 2 ( $\mathrm{n}=162$ for group $1 ; \mathrm{n}=165$ for group 2), and 3 pasture management groups for block 3 ( $\mathrm{n}=107$ for group 1 ; $\mathrm{n}=119$ for group $2 ; \mathrm{n}=110$ for group 3$)$.

On d 0, BW (mean = $191 \pm 2.3 \mathrm{~kg})$ were recorded and implants were administered using product-specific devices for each implant. Persons employed by the study site with appropriate training and experience administered implants according to product labels and instructions. Implants were placed subcutaneously in the middle onethird of the back of one ear per each animal and at least $2.5 \mathrm{~cm}$ from ear tags. Evidence of preexisting implants was not detected during treatment administration on $\mathrm{d}$ 0 . Preparation of implant sites before treatment was as described by Selk et al. (2006) and Cleale et al. (2015). Cattle with clean and dry ears were implanted without cleaning. Cattle with ears that were wet or covered with manure or mud were scrubbed with a brush soaked in disinfectant solution (Nolvasan; Zoetis) before implanting using a "scrape, brush, and disinfect" technique on the ear. Implant device stylets were cleaned in disinfectant solution after each animal was treated. Following implant administration, implant sites were lightly palpated to confirm administration was successful.

Over approximately the first $70 \mathrm{~d}$ following treatment (February 25, 2016, to April 15, 2016), cattle in all management groups were housed in small pastures (traps) and grazed dormant winter grass supplemented with freechoice bermudagrass (Cynodon dactylon) hay and up to $1.32 \mathrm{~kg} /$ animal per day of $26 \% \mathrm{CP}$ concentrate (Table $2)$; additional mineral and salt supplement was not offered during the first $60 \mathrm{~d}$. After cattle were weighed on d 70, those assigned to block 1 and block 2 grazed native pastures with approximate botanical composition of $25 \%$ big bluestem (Andropogon gerardii), 25\% indiangrass (Sorghastrum nutans), 25\% switchgrass (Panicum virgatum), 10\% fescue (Festuca arundinacea), and 15\% other (weeds and so on) at a stocking density of approximately $1.01 \mathrm{ha} /$ animal through completion of the study on d 200 . After d 70, cattle in block 3 grazed pastures containing $70 \%$ bermudagrass (Cynodon dactylon), 25\% fescue (Festuca arundinacea), and $5 \%$ other (weeds and so on) at a stocking density of approximately $0.49 \mathrm{ha} /$ animal through completion of the study. Water was available ad libitum from bodies of water (e.g., ponds). After April 15, 2016, $26 \%$ CP concentrates were offered at feeding levels dependent on visible assessment of pasture forage maturity. In addition, from d 60 to study completion, mineral-salt supplement was offered. Records were maintained of the pasture on which each animal was located throughout the study. A record of dates and quantities of supplemental feeds provided to each pasture was maintained, but unconsumed quantities of hay and supplement were not measured. These data are summarized across pasture management groups in Table 3.

\section{Data Collected}

The study centered on measurement of full BW and health of steers so that ADG could be computed. Scales used to weigh cattle were inspected and calibrated within 12 mo from d 0 of the study. Individual animal BW were obtained before treatment on $\mathrm{d} 0$, then on $\mathrm{d} 70$, and at completion of the study on d 200, and computations of ADG were based on full BW. Cattle were observed daily for potential adverse reactions and health abnormalities and to ensure adequate pasture, supplement, and water availability. Steers that exhibited clinical signs consistent with bovine respiratory disease (BRD) were restrained and body temperatures were measured; those that were febrile (body temperature $\geq 40^{\circ} \mathrm{C}$ ) were treated with tulathromycin at the labeled dose or florfenicol at the labeled dose. Animals with clinical signs of BRD but with body temperature $<40^{\circ} \mathrm{C}$ did not receive antibiotic treatment. Products and doses administered were documented, and cattle treated 3 or more times for BRD were considered to have chronic respiratory disease. Animals with signs of foot rot were treated with ceftiofur hydrochloride, and pinkeye was treated with ceftiofur hydrochloride or oxytetracycline. A component of daily observations was to document suspected adverse drug events potentially related to experimental treatments, but none were observed. Treatment and return to pasture was permitted for routine BRD, pinkeye, foot rot, or other illnesses. When animal welfare was compromised, steers were removed from study, and the cause of animal removal was documented. Once removed, steers were not returned to pastures with

Table 2. Guaranteed analysis of commercial $26 \%$ CP concentrate supplement ${ }^{1}$

\begin{tabular}{lc} 
Item & Value \\
\hline Ingredient composition, 90\% DM basis, \% & \\
Cottonseed meal & 46.32 \\
Wheat middlings & 36.56 \\
Corn gluten 16\% CP & 4.87 \\
Limestone 38\% Ca & 2.44 \\
Molasses & 7.31 \\
Mineral mix & 2.44 \\
Rumensin 90 & 0.06 \\
Formulated nutrient composition, DM basis & \\
CP, \% & 26.0 \\
NE \\
, Mcal/kg & 1.52 \\
NE ${ }_{\mathrm{g}}$, Mcal/kg & 0.97 \\
Crude fat, \% & 2.54 \\
NDF, \% & 27.12 \\
Calcium, \% & 1.68 \\
Phosphorus, \% & 1.25 \\
Potassium, \% & 0.5 \\
\hline
\end{tabular}

${ }^{1}$ Mid America Feeds Inc. (Talala, OK). Feeding instructions: 0.45 to $1.8 \mathrm{~kg} / \mathrm{head}$ per day with good forage and water. 
study animals. One moribund animal was euthanized in accordance with AVMA (2013) because of a broken leg.

Implant sites were observed when animals were weighed on d 70, and observations were documented. Implanted ears on each animal were palpated to document presence or absence of the implant ( $1=$ present, $0=$ absent $)$ and whether local implant site reactions were evident (e.g., evidence of abscess); data were summarized as previously described (Cleale et al., 2015).

\section{Statistical Analysis}

Animal was the experimental unit in analysis of all variables of interest. Based on BW measured on d 0, 70, and 200, BW gains and ADG were computed for the intervals from d 0 to 70 , d 70 to 200, and d 0 to 200. Primary study conclusions were based on data from all enrolled animals that completed the study, regardless of whether the implant was lost. However, analysis of BW gain data was also conducted for only animals that did or did not lose

Table 3. Summary of supplemental feed offered across pasture management groups

\begin{tabular}{|c|c|c|c|}
\hline \multirow[b]{2}{*}{ Study days ${ }^{1}$} & \multicolumn{3}{|c|}{ Daily averages per animal } \\
\hline & $\begin{array}{c}26 \% \mathrm{CP} \\
\text { concentrate, } \\
\mathrm{kg} / \mathrm{d}\end{array}$ & $\begin{array}{c}\text { Bermudagrass } \\
\text { hay, kg/d }\end{array}$ & $\begin{array}{c}\text { Mineral, }{ }^{2,3} \\
\text { g/d }\end{array}$ \\
\hline 1 to 20 & 1.32 & 2.81 & 0.00 \\
\hline 21 to 40 & 1.32 & 3.13 & 0.00 \\
\hline 41 to 60 & 1.23 & 1.77 & 7.3 \\
\hline 61 to 80 & 1.18 & 1.50 & 21.4 \\
\hline 81 to 100 & 0.23 & 0.05 & 79.7 \\
\hline 101 to 120 & 0.14 & 0.00 & 102.4 \\
\hline 121 to 140 & 0.45 & 0.00 & 46.5 \\
\hline 141 to 160 & 1.14 & 0.00 & 53.7 \\
\hline 161 to 180 & 1.14 & 0.00 & 27.5 \\
\hline 181 to 200 & 1.04 & 0.00 & 20.3 \\
\hline
\end{tabular}

${ }^{1} \mathrm{~d} 1$ for block 1 = February 25, 2016; d 200 for block 3 = August 26, 2016.

${ }^{2}$ Western Feed Mills Inc. (Cedar Vale, KS). Feeding instructions: $91 \mathrm{~g} / \mathrm{d}$ to provide $350 \mathrm{mg}$ of chlortetracycline for control of bacterial pneumonia in cattle associated with shipping fever complex caused by Pasteurella spp. susceptible to chlortetracycline. For control of active infection of Anaplasma marginale susceptible to chlortetracycline in cattle less than $320 \mathrm{~kg}$.

${ }^{3}$ Guaranteed analysis (90\% DM basis): 18.0 to $21.6 \%$ calcium, $\geq 1.5 \%$ phosphorus, 18.0 to $21.6 \%$ salt, $\geq 1.0 \%$ magnesium, $\geq 0.25 \%$ potassium, $\geq 150 \mathrm{mg} / \mathrm{kg}$ copper, $\geq 400 \mathrm{mg} / \mathrm{kg}$ iodine (as ethylenediamine dihydroiodide), $\geq 2.2 \mathrm{mg} / \mathrm{kg}$ selenium, $\geq 600 \mathrm{mg} / \mathrm{kg}$ zinc, $\geq 110,132 \mathrm{IU}$ of vitamin $\mathrm{A} / \mathrm{kg}$, and $3.85 \mathrm{~g} / \mathrm{kg}$ chlortetracycline. implants on or before d 70. Purchase prices for stocker cattle, prices received for feeder cattle exiting the study, implant costs, and estimated morbidity costs associated with labor and products purchased to treat animals were used to perform a partial budget analysis of economic implications resulting from implant treatment selections.

All study animals were steers on d 0 . However, approximately $32 \%$ were not castrated until at least $14 \mathrm{~d}$ before d 0 . Allocation and randomization of animals to treatments accounted for whether animals were steers or bulls at arrival, and approximately equal numbers of steers that arrived as bulls were assigned to each experimental treatment (Table 1). Normally distributed response criteria were analyzed by PROC MIXED procedures of SAS (SAS Institute Inc., Cary, NC) to evaluate the fixed effects of treatment, sex at the time of arrival (steer or banded bull), and the treatment by sex interaction, and random effects were pasture management group within block, treatment by pasture management group within block by treatment interaction, and residual. The treatment by sex interaction was not significant, and the final model considered fixed effects of treatment and sex at the time of arrival (steer or banded bull) and random effects of pasture management group within block, treatment by pasture management group within block by treatment interaction, and residual. Effects of sex were detected for some dependent variables, but because treatment by sex interactions were not significant and the effect of sex at arrival was not of primary interest, these results are not reported herein. Treatment least squares means and SE are reported. Treatment differences were evaluated with a protected 2 -tailed $t$-test at the $5 \%$ level of significance.

Frequency results (i.e., categorical variables) pertaining to implant retention, death, culling, incidence of clinical disease, and number of treatments administered were analyzed by logistic regression using the PROC GLIMMIX procedure of SAS to evaluate the fixed effects of treatment and sex at the time of arrival and random effects of pasture management group within block, treatment by pasture management group within block by treatment interaction, and residual. Treatment differences were evaluated with a protected 2-tailed $t$-test at the $5 \%$ level of significance.

Supplemental feed offered was summarized but not statistically analyzed because quantities of feed refusals were not measured. Furthermore, because all treatments were equally represented within an animal management group, there was no treatment bias with respect to level of supplementation.

\section{RESULTS AND DISCUSSION}

\section{Animal Management}

Table 3 provides an overview across pasture management groups of quantities of $26 \% \mathrm{CP}$ concentrate, ber- 
mudagrass hay, and mineral mix offered during each 20-d interval throughout the course of the study. During a 5 -d period that included April 19 to 23, 2016, cattle were pulse dosed with medicated feed intended to deliver $22 \mathrm{mg}$ of chlortetracycline $/ \mathrm{kg}$ of $\mathrm{BW}$, an approved approach for treatment of BRD. Following a 2-d period with no treatment, pulse dosing with $22 \mathrm{mg}$ of chlortetracycline $/ \mathrm{kg}$ of BW resumed for another 5-d period that included April 26 to March 1, 2016. Supplementation of pasture with bermudagrass hay and $26 \% \mathrm{CP}$ concentrate occurred primarily during the first $70 \mathrm{~d}$, when available pasture forage consisted of dormant grass. Beyond d 70 (mid-April) cattle grazed spring-summer grass, which eliminated the need to supplement with bermudagrass hay for the remainder of the study. Supplementation with $26 \%$ CP concentrate decreased dramatically during spring-summer grazing but began to increase from approximately late-June through completion of the study as grass matured.

Of 330 steers enrolled to SOG, 320 completed the study (Table 4). Six SOG steers died between enrollment and d 70 due to BRD, and an additional 4 animals were removed during processing on d 70 due to chronic BRD. No animals were removed from SOG after d 70. Of 328 steers enrolled to REVG, 314 completed the study. Eight REVG steers died from BRD between enrollment and d 70 and 1 died of septicemia; 3 others were removed during processing on d 70 due to chronic BRD. Between d 70 and termination of the study, an additional 2 animals died. Cause of death for these 2 animals could not be determined be- cause predators damaged carcasses. Of 328 steers enrolled to ENC, 314 completed the study. Seven steers from this treatment died from BRD between enrollment and d 70 and 1 was euthanized on d 68 for humane reasons due to a broken leg; an additional 2 steers were removed during processing on d 70 due to chronic BRD. Between d 70 and termination of the study, an additional 2 animals died, but cause of death could not be determined due to carcass mutilation by predators. An additional 2 animals were not present at the time final BW were measured on d 200 and were presumed dead or lost. Overall, cause of culling or death for 30 of the 38 animals that did not complete the study was BRD, but there was no treatment-related difference in culling or death losses specifically due to BRD $(P=0.9028)$. There was no evidence that mortality $(P$ $=0.6202)$ or culling $(P=0.7501)$ incidence was different between treatments, and as a result the number of cattle that completed the study was not different between treatments $(P=0.6994)$.

\section{d-70 Implant Observations}

Of the 324 SOG animals that were observed on $d 70$ (Table 5), implants were located in 300 steers, yielding a retention rate of $92.5 \%$. A total of 319 REVG were observed on d 70, and implants were located in 307 steers, yielding a retention rate of $96.2 \%$. Finally, of $320 \mathrm{ENC}$ steers observed on d 70, implants were located in 281 , yielding a retention rate of $87.8 \%$. The number of cattle with retained implants on d 70 was different across treat-

Table 4. Summary of animal removal data

\begin{tabular}{lrrrr} 
& \multicolumn{3}{c}{ Treatment $^{1}$} & \\
\cline { 2 - 4 } Item & SOG & REVG & ENC & P-value $^{2}$ \\
\hline No. enrolled & 330 & 328 & 328 & - \\
No. dead d 0 to 70 & 6 & 9 & 8 & 0.6202 \\
No. culled on d 70 & 4 & 3 & 2 & 0.7501 \\
No. present at d 70 & 320 & 316 & 318 & 0.7635 \\
No. dead d 70 to 200 & 0 & 2 & 2 & NE $^{3}$ \\
No. missing at d 200 & 0 & 0 & 2 & NE \\
No. present at d 200 & 320 & 314 & 314 & 0.6994 \\
Dead or cull removal reasons & & & & \\
Bovine respiratory disease & 10 & 11 & 9 & 0.9028 \\
Broken leg (euthanized) & 0 & 0 & 1 & NE \\
Septicemia & 0 & 1 & 0 & NE \\
Cause of death unknown due to predators & 0 & 2 & 2 & NE \\
Other unknown (missing at d 200) & 0 & 0 & 2 & NE \\
\hline
\end{tabular}

${ }^{1}$ SOG = Synovex One Grass (Zoetis, Parsippany, NJ); REVG = Revalor-G (Merck, Madison, $\mathrm{NJ}) ; \mathrm{ENC}=$ Encore (Elanco, Indianapolis, IN).

'Data were analyzed by logistic regression using the PROC GLIMMIX procedure of SAS (SAS Institute Inc., Cary, NC) to evaluate the fixed effects of treatment and sex at the time of arrival and random effects of pasture management group within block, treatment by pasture management group within block by treatment interaction, and residual.

${ }^{3} \mathrm{NE}=$ nonestimable due to inadequate data to allow model convergence. 
ments $(P=0.0031)$, with retention by cattle treated with ENC significantly less $(P \leq 0.05)$ than REVG and SOG; implant retention was not different between REVG and SOG $(P>0.05)$. The number of SOG, REVG, and ENC cattle that lost implants was 24,12 , and 39 , respectively $(P=0.0042)$; implant loss was significantly different for REVG and ENC $(P \leq 0.05)$, but implant loss for SOG cattle was intermediate and not different from either REVG or ENC $(P>0.05)$. Retention of SOG implants in the present study was less than was previously shown in 2 studies by Cleale et al. (2015), where SOG implant retention rates in cattle treated by the same procedures as those used herein were 100 and $97.6 \%$, respectively. Previous studies evaluating implant retention in cattle treated with estradiol-containing silicone implants have reported similar results to those reported here (Mathison and Stobbs, 1983). Parrott et al. (1985) reported that reduced retention of silicone implants is a function of the physical properties of the implant, hygiene during application, placement location in the ear, and physical factors (e.g., head shaking soon after treatment).

A summary of steers on each treatment showing evidence of abscesses or fluid at the implant site is presented in Table 5. Implant site abscess incidence was affected by treatment $(P=0.0333)$, with more animals treated with REVG showing evidence of abscesses at implant sites than steers treated with ENC $(P \leq 0.05)$; an explanation for this observation is not evident. The number of SOG cattle with evidence of abscesses at implant sites was not different from either REVG or ENC $(P>0.05)$. Presence of fluid at implant sites was not affected by treatment $(P=$ $0.1358)$, nor was overall implant defect rate $(P=0.2999)$, which was defined as the sum of animals on each treatment with evidence of lost, abscessed, or fluid-surrounded implants.

\section{BW, Weight Gain, and ADG}

The primary basis for study conclusions centered on results that included all animals enrolled into the study, regardless of whether or not implants were documented missing on $\mathrm{d} 70$. Body weights of cattle on d 0 were not different among treatments $(P=0.8312$; Table 6$)$. Similarly BW were not different on d 70 (mean $=232 \pm 3.3 \mathrm{~kg}$; $P=0.9254$ ), indicating implants performed comparably during the early stages of the grazing period. By d 200, however, cattle treated with SOG weighed $391.2 \mathrm{~kg}$, which was more than REVG cattle $(380.7 \mathrm{~kg})$ or cattle treated with ENC $(381.4 \mathrm{~kg} ; P \leq 0.05)$. Final BW of cattle treated with REVG was not different from final BW of cattle treated with ENC $(P>0.05)$.

Body weight gains from d 0 to 70 averaged $41.6 \mathrm{~kg} /$ steer and were not affected by treatment $(P=0.9721$; Table 6$)$. However, BW gained by SOG cattle over the latter 130 d of the study (159.8 kg) and over the entire 200-d study $(200.2 \mathrm{~kg})$ were greater than for cattle treated with REVG (150.2 and $190.7 \mathrm{~kg}$, respectively) or ENC (150.1 and 190.8 $\mathrm{kg}$, respectively; $P \leq 0.05$ ), but BW gains by REVG and ENC were not different from each other through either of these intervals. Over the 200-d study, cattle treated with

Table 5. Summary of implant status data through $70 \mathrm{~d}$ of study

\begin{tabular}{lcccc} 
& \multicolumn{4}{c}{ Treatment $^{1}$} \\
\cline { 2 - 4 } Item & SOG & REVG & ENC & P-value $^{2}$ \\
\hline No. enrolled & 330 & 328 & 328 & - \\
Implant status & & & & \\
$\quad$ Animals with data on d 70, no. & 324 & 319 & 320 & - \\
$\quad$ Lost implants, no. & $24^{\mathrm{ab}}$ & $12^{\mathrm{b}}$ & $39^{\mathrm{a}}$ & 0.0042 \\
$\quad$ Retained implants, no. & $300^{\mathrm{b}}$ & $307^{\mathrm{b}}$ & $281^{\mathrm{a}}$ & 0.0031 \\
$\quad$ Retention rate, \% & 92.5 & 96.2 & 87.8 & - \\
Of animals with retained implants on d 70 & & & & \\
$\quad$ Abscessed, no. (\%) & $7^{\mathrm{ab}}(2.3)$ & $15^{\mathrm{b}}(4.9)$ & $3^{\mathrm{a}}(1.1)$ & 0.0333 \\
$\quad$ With fluid, no. (\%) & $7(2.3)$ & $2(0.7)$ & $2(0.7)$ & 0.1358 \\
Of animals with data on d 70 & & & & \\
$\quad$ Lost, abscessed, or with fluid, no. & 38 & 29 & 44 & 0.2999 \\
Lost, abscessed, or with fluid, \% & 11.7 & 9.1 & 13.8 & - \\
\hline
\end{tabular}

a,bValues in the same row with different superscripts are different $(P \leq 0.05)$.

${ }^{1} \mathrm{SOG}=$ Synovex One Grass (Zoetis, Parsippany, NJ); REVG = Revalor to G (Merck, Madison, $\mathrm{NJ}) ; \mathrm{ENC}=$ Encore (Elanco, Indianapolis, IN).

${ }^{2}$ Data were analyzed by logistic regression using the PROC GLIMMIX procedure of SAS (SAS Institute Inc., Cary, NC) to evaluate the fixed effects of treatment and sex at the time of arrival and random effects of pasture management group within block, treatment by pasture management group within block by treatment interaction, and residual. 
SOG gained an average of $9.5 \mathrm{~kg}$ of BW more than steers treated with REVG or ENC $(P \leq 0.05)$.

Rates of BW gain were not different $(P=0.9721)$ among treatments over the first $70 \mathrm{~d}$ of the study and averaged $0.58 \mathrm{~kg} / \mathrm{d}$ (Table 6 ). Over the last $130 \mathrm{~d}$ of the study, however, ADG by all treatments was more than during the initial 70-d interval, likely due to increased forage quality and DM availability after d 70. Between d 70 and 200, ADG by cattle treated with SOG $(1.23 \mathrm{~kg} / \mathrm{d})$ was greater $(P \leq 0.05)$ than ADG for either REVG $(1.16 \mathrm{~kg} / \mathrm{d})$ or ENC $(1.16 \mathrm{~kg} / \mathrm{d})$. Over the entire $200-\mathrm{d}$ study, cattle implanted with SOG gained $0.05 \mathrm{~kg} / \mathrm{d}$ more than cattle implanted with either REVG or ENC $(P \leq 0.05)$.

Table 7 summarizes ADG data over the entirety of the 200-d study based on 70-d implant observations for steers completing the study that either retained or did not retain implants. Considering only data from animals that retained implants, ADG by SOG steers was $1.01 \mathrm{~kg} / \mathrm{d}$, which was greater $(P<0.05)$ than ADG by steers treated with REVG $(0.96 \mathrm{~kg} / \mathrm{d})$ or ENC $(0.97 \mathrm{~kg} / \mathrm{d})$. Despite differences in proportions of implants lost between treatments and differences in ADG by steers that lost versus those that retained implants, the overall effect of lost implants on overall ADG for each treatment was between 0.00 and $-0.01 \mathrm{~kg} / \mathrm{d}$. For those animals that lost implants, ADG over the entirety of the study by steers treated with SOG, REVG, or ENC were $0.84,0.83$, and $0.86 \mathrm{~kg} / \mathrm{d}$, respectively $(P=0.7959)$. If one considers ADG by animals that lost implants to be an approximate representation of growth rates for nontreated control steers, then over the 200-d grazing period the effect of implanting SOG steers was $20.2 \%$, the effect of implanting REVG steers was $15.7 \%$, and the effect of implanting ENC steers was $12.8 \%$.

Cleale et al. (2012) showed that addition of the polymer coating to 8-pellet implants containing $28 \mathrm{mg}$ of estradiol benzoate and $200 \mathrm{mg}$ of trenbolone acetate effectively modified payout of estradiol benzoate and trenbolone acetate from approximately $120 \mathrm{~d}$ for traditional uncoated implants (Synovex Plus; Zoetis) to up to $200 \mathrm{~d}$ with coated implants containing the same doses of active ingredients (Synovex One Feedlot; Zoetis). Later, Cleale et al. (2015) showed in pastured steers implanted with SOG that ADG increased over 200-d grazing periods by $20.5 \%$ compared with sham-implanted controls in one study and $16.7 \%$ in a second study, results that are similar to the present study. Data pooled from 4 studies conducted to evaluate product efficacy showed that over 107- to 116-d grazing periods, ADG by steers treated with REVG $(0.94$ $\mathrm{kg} / \mathrm{d}$ ) was $14.6 \%$ more than ADG by negative controls $(0.82 \mathrm{~kg} / \mathrm{d} ; \mathrm{FDA}, 1996)$, a result similar to the effect of REVG in the present study. Kuhl (1997) also presented data from 94-d grazing studies showing ADG by steers implanted with REVG $(0.75 \mathrm{~kg} / \mathrm{d})$ was $16.1 \%$ more than nonimplanted controls $(0.65 \mathrm{~kg} / \mathrm{d})$. Increased ADG of 11 to $15 \%$ by steers treated with estradiol-containing silicone implants such as Compudose and ENC (also referred to as Compudose 400) were shown by Utley et al. (1980) and Mathison and Stobbs (1983).

\section{Morbidity Data}

Over the course of the study, approximately $29 \%$ of animals enrolled were treated at least once for BRD, pink-

Table 6. Summary of weight gain data for animals that completed the study (least squares means \pm SE excluding dead and culled cattle)

\begin{tabular}{|c|c|c|c|c|}
\hline \multirow[b]{2}{*}{ Item } & \multicolumn{3}{|c|}{ Treatment $^{1}$} & \multirow[b]{2}{*}{$P$-value } \\
\hline & SOG & REVG & ENC & \\
\hline No. completing study (200 d) & 320 & 314 & 314 & - \\
\hline \multicolumn{5}{|l|}{$\mathrm{BW}, \mathrm{kg}$} \\
\hline d 0 & $191.2 \pm 2.3$ & $190.1 \pm 2.3$ & $190.7 \pm 2.3$ & 0.8312 \\
\hline d 70 & $232.1 \pm 3.3$ & $231.2 \pm 3.3$ & $232.0 \pm 3.3$ & 0.9254 \\
\hline d 200 & $391.2 \pm 8.8^{a}$ & $380.7 \pm 8.8^{b}$ & $381.4 \pm 8.8^{b}$ & 0.0034 \\
\hline \multicolumn{5}{|l|}{ Weight gain, kg/steer } \\
\hline d 0 to 70 & $40.4 \pm 3.3$ & $40.6 \pm 3.3$ & $40.8 \pm 3.3$ & 0.9721 \\
\hline d 70 to 200 & $159.8 \pm 10.5^{\mathrm{a}}$ & $150.2 \pm 10.5^{b}$ & $150.1 \pm 10.5^{b}$ & $<0.0001$ \\
\hline d 0 to 200 & $200.2 \pm 9.0^{\mathrm{a}}$ & $190.7 \pm 9.0^{b}$ & $190.8 \pm 9.0^{\mathrm{b}}$ & 0.0013 \\
\hline \multicolumn{5}{|l|}{ ADG, kg/d } \\
\hline d 0 to 70 & $0.58 \pm 0.05$ & $0.59 \pm 0.05$ & $0.58 \pm 0.05$ & 0.9721 \\
\hline d 70 to 200 & $1.23 \pm 0.08^{a}$ & $1.16 \pm 0.08^{b}$ & $1.16 \pm 0.08^{b}$ & $<0.0001$ \\
\hline d 0 to 200 & $1.00 \pm 0.04^{a}$ & $0.95 \pm 0.04^{b}$ & $0.95 \pm 0.04^{b}$ & 0.0013 \\
\hline
\end{tabular}

${ }^{a, b}$ Means in the same row with different superscripts are different by protected $t$-test $(P<0.05)$. ${ }^{1}$ SOG = Synovex One Grass (Zoetis, Parsippany, NJ); REVG = Revalor-G (Merck, Madison, $\mathrm{NJ}) ; \mathrm{ENC}=$ Encore $($ Elanco, Indianapolis, IN). 
Table 7. Summary of ADG by steers completing the study that did or did not lose implants before $d 70$ (least squares means \pm SE excluding dead and culled cattle)

\begin{tabular}{|c|c|c|c|c|}
\hline \multirow[b]{2}{*}{ Item } & \multicolumn{3}{|c|}{ Treatment $^{1}$} & \multirow[b]{2}{*}{$P$-value } \\
\hline & SOG & REVG & ENC & \\
\hline \multicolumn{5}{|l|}{ Retained implants } \\
\hline No. of steers & 297 & 302 & 275 & - \\
\hline $\mathrm{ADG}, \mathrm{kg} / \mathrm{d}$ & $1.01 \pm 0.05^{a}$ & $0.96 \pm 0.05^{b}$ & $0.97 \pm 0.05^{b}$ & 0.0012 \\
\hline \multicolumn{5}{|l|}{ Lost implants } \\
\hline No. of steers & 23 & 12 & 39 & - \\
\hline $\mathrm{ADG}, \mathrm{kg} / \mathrm{d}$ & $0.84 \pm 0.06$ & $0.83 \pm 0.07$ & $0.86 \pm 0.06$ & 0.7959 \\
\hline ADG, \% increase above lost & 20.2 & 15.7 & 12.8 & - \\
\hline
\end{tabular}

eye, or foot rot, but overall frequencies were not different between treatments $(P=0.9384$; Table 8$)$. Data also did not show any treatment-related differences on the number of cattle treated at least twice $(P=0.9827)$ or at least 3 times for these disorders $(P \geq 0.1761)$. For respiratory disease, approximately $14 \%$ of SOG cattle, $16 \%$ of REVG cattle, and $16 \%$ of ENC cattle were treated, respectively $(P=0.7124)$. Likewise for pinkeye, 5,4 , and $5 \%$ of cattle were treated, respectively, with SOG, REVG, and ENC ( $P$ $=0.8394)$. Incidence of foot rot was low overall and not different between treatments $(P=0.3274)$.

\section{Partial Budget Economic Analysis}

Table 9 summarizes the partial budget analysis based on average purchase price paid for cattle enrolled into the study, average sale value of cattle as feeders after $200 \mathrm{~d}$ on study, internet retailer prices for implant treatments, and estimated morbidity expenses (medicines, supplies, and labor). Calculations were performed both with and without consideration of dead and culled animals. Assumptions used in calculations are presented as footnotes to Table 9. Average purchase price for stockers averaged about $\$ 932$

Table 8. Summary of morbidity data

\begin{tabular}{lcccc} 
& \multicolumn{3}{c}{ Treatment $^{1}$} \\
\cline { 2 - 4 } Item & SOG & REVG & ENC & P-value $^{2}$ \\
\hline No. enrolled & 330 & 328 & 328 & - \\
Treated at least once, no. (\%) & $93(28.4)$ & $97(29.4)$ & $92(28.0)$ & 0.9384 \\
Treated at least twice, no. (\%) & $26(10.0)$ & $28(10.5)$ & $28(10.2)$ & 0.9827 \\
Treated at least thrice, no. (\%) & $1(0.4)$ & $4(1.6)$ & $7(2.8)$ & 0.1761 \\
Respiratory disease & & & & \\
$\quad$ Treated at least once, no. (\%) & $48(14.3)$ & $55(16.3)$ & $57(16.4)$ & 0.7124 \\
$\quad$ Treatments given, no. (no./enrollee) & $60(0.177)$ & $73(0.217)$ & $74(0.216)$ & 0.4705 \\
Pinkeye & $17(4.8)$ & $21(4.2)$ & $20(5.3)$ & 0.8394 \\
$\quad$ Treated at least once, no. (\%) & $21(0.058)$ & $27(0.053)$ & $27(0.069)$ & 0.7328 \\
$\quad$ Treatments given, no. (no./enrollee) & & & & \\
Foot rot & $21(1.4)$ & $13(0.5)$ & $12(0.1)$ & 0.3274 \\
$\quad$ Treated at least once, no. (\%) & $30(0.019)$ & $19(0.010)$ & $21(0.012)$ & 0.4644 \\
$\quad$ Treatments given, no. (no./enrollee) & & & \\
\hline
\end{tabular}

${ }^{1}$ SOG $=$ Synovex One Grass (Zoetis, Parsippany, NJ); REVG = Revalor-G (Merck, Madison, $\mathrm{NJ}) ; \mathrm{ENC}=$ Encore (Elanco, Indianapolis, IN)

${ }^{2}$ Data were analyzed by logistic regression using the PROC GLIMMIX procedure of SAS (SAS Institute Inc., Cary, NC) to evaluate the fixed effects of treatment and sex at the time of arrival and random effects of pasture management group within block, treatment by pasture management group within block by treatment interaction, and residual. 
Table 9. Partial budget economic analysis of treatment choice (least squares means \pm SE)

\begin{tabular}{|c|c|c|c|c|}
\hline \multirow[b]{2}{*}{ Item } & \multicolumn{3}{|c|}{ Treatment $^{1}$} & \multirow[b]{2}{*}{$P$-value } \\
\hline & SOG & REVG & ENC & \\
\hline \multicolumn{5}{|l|}{ Deads and culls excluded } \\
\hline Stocker purchase price at $\$ 221.75 / 45.4 \mathrm{~kg},{ }^{2} \$$ & $934.59 \pm 11.05$ & $929.33 \pm 11.07$ & $932.22 \pm 11.08$ & 0.8312 \\
\hline Feeder sale price at $\$ 142.50 / 45.4 \mathrm{~kg},{ }^{2} \$$ & $1,228.97 \pm 27.60^{a}$ & $1,196.04 \pm 27.61^{b}$ & $1,198.04 \pm 27.62^{b}$ & 0.0034 \\
\hline Gross value of weight gained, \$/animal & $294.82 \pm 28.58^{a}$ & $266.91 \pm 28.58^{b}$ & $266.09 \pm 28.59^{b}$ & 0.0027 \\
\hline Implant cost, ${ }^{3} \$ /$ dose & 4.95 & 1.39 & 3.00 & - \\
\hline Value of gain minus implant cost, $\$$ & $289.87 \pm 28.58^{a}$ & $265.52 \pm 28.58^{b}$ & $263.09 \pm 28.59^{b}$ & 0.0067 \\
\hline Morbidity cost, ${ }^{4} \$$ /animal & $6.17 \pm 0.90$ & $6.15 \pm 0.90$ & $6.39 \pm 0.90$ & 0.9360 \\
\hline Value of gain minus implant and morbidity cost, $\$$ & $283.21 \pm 29.75^{a}$ & $258.92 \pm 29.75^{b}$ & $256.24 \pm 29.76^{b}$ & 0.0075 \\
\hline \multicolumn{5}{|l|}{ Deads and culls included 5} \\
\hline Stocker purchase price at $\$ 221.75 / 45.4 \mathrm{~kg},{ }^{2} \$$ & $933.28 \pm 10.99$ & $927.48 \pm 10.99$ & $928.95 \pm 11.00$ & 0.7774 \\
\hline Feeder sale price at $\$ 142.50 / 45.4 \mathrm{~kg},{ }^{2} \$$ & $1,199.75 \pm 27.18^{a}$ & $1,150.69 \pm 27.18^{b}$ & $1,156.75 \pm 27.23^{b}$ & 0.0290 \\
\hline Gross value of weight gained, \$/animal & $266.46 \pm 28.71^{\mathrm{a}}$ & $223.20 \pm 28.72^{b}$ & $227.60 \pm 28.77^{\mathrm{b}}$ & 0.0322 \\
\hline Implant cost, ${ }^{3} \$ /$ dose & 4.95 & 1.39 & 3.00 & - \\
\hline Value of gain minus implant cost, $\$$ & $261.51 \pm 28.72^{a}$ & $221.81 \pm 28.72^{b}$ & $224.60 \pm 28.77^{b}$ & 0.0490 \\
\hline Morbidity cost, ${ }^{4}$ \$/animal & $6.79 \pm 0.85$ & $7.25 \pm 0.85$ & $7.26 \pm 0.85$ & 0.7749 \\
\hline Value of gain minus implant and morbidity cost, $\$$ & $254.15 \pm 29.85^{a}$ & $213.80 \pm 29.86^{b}$ & $216.63 \pm 29.90^{b}$ & 0.0521 \\
\hline
\end{tabular}

a,bMeans in the same row with different superscripts are different by protected or unprotected $t$-tests $(P<0.05)$.

${ }^{1} \mathrm{SOG}=$ Synovex One Grass (Zoetis, Parsippany, NJ); REVG = Revalor-G (Merck, Madison, NJ); ENC = Encore (Elanco, Indianapolis, IN).

${ }^{2}$ Cattle prices are the average paid for $193-\mathrm{kg}$ steers when the study started, $\$ 4.88 / \mathrm{kg}$; value at completion of the study was the average sale price received for $386-\mathrm{kg}$ steers, $\$ 3.14 / \mathrm{kg}$.

${ }^{3}$ Implant prices obtained from www.valleyvet.com on September 18, 2016.

${ }^{4}$ Cattle were treated for bovine respiratory disease, pinkeye, and foot rot with Draxxin (Zoetis), Nuflor (Merck), Excenel (Zoetis), or Noromycin 300 LA (Norbrook, Overland Park, KS); antibiotic prices were obtained at www.valleyvet.com on September 18, 2016. Morbidity costs were based on dose administered, route of administration, and assumed labor costs at $\$ 20 /$ man-hour. See Table 8 for a summary of number of animals treated and number of treatments administered to each treatment group.

${ }^{5}$ All culls were removed after weighing during processing on d 70 . Culls were assigned a value of $\$ 3.14 / \mathrm{kg}$, and value at time of removal was computed based on d-70 BW. Loss on dead animals was estimated as purchase price and no return.

per animal and was not different between treatments. At study termination, however, cattle treated with SOG were valued at $\$ 1,229$ each, whereas those treated with either REVG or ENC were valued at approximately $\$ 1,197$ ( $P$ $=0.0034)$. Subtracting purchase price of stockers from the value of feeder cattle yielded gross value of the BW gained, which was $\$ 295$ for SOG and $\$ 267$ for REVG and ENC; value of gain for SOG was greater than REVG or ENC $(P<0.05)$. Value of BW gained after consideration of the implant costs for each treatment showed that gross value of animals treated with SOG remained significantly more than that for REVG and ENC. Costs associated with therapeutic treatments averaged about $\$ 6$ per enrolled animal and were not different among treatments $(P>0.9360)$. The final calculation, which was the value of BW gained minus implant and therapeutic treatment costs, showed that value of BW gain was $\$ 283$ for cattle treated with SOG, $\$ 259$ for cattle treated with REVG, and $\$ 256$ for cattle treated with ENC; SOG was greater than REVG and ENC $(P<0.05)$, but REVG and ENC were not different from each other. The SOG treatment increased the value of cattle by over $\$ 24$ compared with REVG and increased the value of cattle by over $\$ 26$ compared with ENC. Conducting computations in a manner that reflected economic losses associated with culled and dead cattle increased the net treatment effect of SOG after implant and morbidity expenses compared with REVG $(\$ 40)$ or $\mathrm{ENC}(\$ 38 ; P=0.0521)$.

\section{IMPLICATIONS}

Through the first $70 \mathrm{~d}$, ADG was similar for all treatment groups, but under the conditions of this study, a single dose of SOG resulted in ADG over the complete 200-d grazing period of $1.01 \mathrm{~kg} / \mathrm{d}$, whereas ADG by steers treated with a single dose of either REVG or ENC were both $0.96 \mathrm{~kg} / \mathrm{d}$. Thus, during this $200-\mathrm{d}$ study ADG by SOG cattle was $5.2 \%$ more than ADG by REVG or ENC cattle. Because cattle treated with SOG grew faster, their gross value at the end of the study was more than other 
treatments studied by at least $\$ 24$ /animal. There was no effect of treatments on morbidity, mortality, or culling rate, and there were no observed adverse effects attributable to experimental treatments.

\section{ACKNOWLEDGMENTS}

Funding was provided by Zoetis. A collaborative effort between Zoetis and Gallery Ranch was used for protocol development, and all data points were defined a priori in the protocol. Ranch employees that were not masked oversaw d-0 randomization and experimental treatment administration. Raw data were observed and recorded by ranch personnel masked to treatments and independent from Zoetis. Zoetis performed biometric analysis of data and worked collaboratively with ranch personnel to report the data.

\section{LITERATURE CITED}

AVMA (American Veterinary Medical Association). 2013. AVMA Guidelines for the Euthanasia of Animals: 2013 Edition. Accessed Dec. 4, 2015. https://www.avma.org/KB/Policies/Documents/ Euthanasia.pdf.

Cleale, R. M., D. T. Bechtol, S. Brewbaker, J. S. Drouillard, J. J. Edmonds, M. Edmonds, B. D. Hunsaker, L. A. Kraft, T. E. Lawrence, and A. R. Waite. 2012. Synovex Plus implants coated with a polymeric, porous film improve performance by beef steers and heifers fed in confinement for up to 200 days. J. Anim. Sci. 90:5056-5066. https:// doi.org/10.2527/jas.2012-5091.

Cleale, R. M., J. J. Edmonds, M. Edmonds, B. D. Hunsaker, L. A. Kraft, L. L. Smith, and T. A. Yazwinski. 2015. Growth promoting hormonal implant pellets coated with a polymeric, porous film pro- mote weight gain by grazing beef heifers and steers for up to 200 days. J. Anim. Sci. 93:1933-1941. https://doi.org/10.2527/jas.2014-8328.

Duckett, S. K., and J. G. Andrae. 2001. Implant strategies in an integrated beef production system. J. Anim. Sci. 79(E. Suppl.):E110E117.

FASS. 2010. Guide for the Care and Use of Agricultural Animals in Research and Teaching. 3rd ed. Fed. Anim. Sci. Soc., Champaign, IL.

Ferguson, T. H., G. F. Needham, and J. F. Wagner. 1988. Compudose $^{\oplus}$ : An implant system for growth promotion and feed efficiency in cattle. J. Control. Release 8:45-54. https://doi.org/10.1016/0168 $-3659(88) 90099-5$.

Kuhl, G. L. 1997. Stocker cattle responses to implants. Pages 51-62 in Proc. OSU Symp.: Impact of Implants on Performance and Carcass Value of Beef Cattle. P-957. Oklahoma Agric. Exp. Stn., Stillwater.

Mathison, G. W., and L. A. Stobbs. 1983. Efficacy of Compudose ${ }^{\mathbb{E}}$ as a growth promotant implant for growing-finishing steers. Can. J. Anim. Sci. 63:75-80. https://doi.org/10.4141/cjas83-009.

Parrott, J. C., R. P. Basson, L. H. Carroll, N. G. Elliston, T. H. Ferguson, P. E. Gorham, H. P. Grueter, J. W. McAskill, and J. F. Wagner. 1985. Factors affecting retention of estradiol-17 $\beta$ silicone rubber implants in ears of steers. J. Anim. Sci. 61:807-813. https://doi.org/ 10.2527/jas1985.614807x.

Selk, G. E., R. R. Reuter, and G. L. Kuhl. 2006. Using growth-promoting implants in stocker cattle. Vet. Clin. North Am. Food Anim. Pract. 22:435-449.

FDA (US Food and Drug Administration). 1996. Freedom of information summary. NADA 140-897-Revalor-G supplemental approval. Accessed Nov. 24, 2015. https://www.fda.gov/ AnimalVeterinary/ Products/ApprovedAnimalDrugProducts/FOIADrugSummaries.

Utley, P. R., C. N. Murphy, C. E. Merchant, and W. C. McCormick. 1980. Evaluation of estradiol removable implants for growing and finishing steers. J. Anim. Sci. 50:221-225. https://doi.org/10.2527/ jas1980.502221x. 